\title{
Differences in cashiers work technique regarding wrist movements when scanning groceries
}

\author{
Palm Peter ${ }^{\mathrm{a}, \mathrm{b}^{*}}$, Johansson Elin ${ }^{\mathrm{c}}$, Kjellberg Katarina ${ }^{\mathrm{c}}$ and Josephson Malin ${ }^{\mathrm{a}}$ \\ ${ }^{a}$ Department of Medical Sciences Occupational and Environmental Medicine, Uppsala University, \\ Ulleråkersvägen 38, S-751 85 Uppsala, Sweden. \\ ${ }^{\mathrm{b}}$ Department of Occupational and Public Health Sciences, Faculty of Health and Occupational Studies, University \\ of Gävle, Centre for Musculoskeletal Research, S-801 76 Gävle Sweden. \\ ${ }^{\mathrm{c}}$ Department of Public Health Sciences, Karolinska Institutet, Norrbacka, 4th floor, S-171 76 Stockholm, Sweden.
}

\begin{abstract}
Checkout cashier work can be repetitive and hand-intensive. Differences in workstyle might explain why some cashiers develop symptoms and other do not. Work technique is one part of the workstyle concept. The aim of this study was to analyze if there were differences in work technique among cashiers in to what extent they use large or small wrist movements when scanning groceries. Wrist movements of 17 cashiers were video recorded. The results revealed large variation among the cashiers in if they use large or small wrist movements when handling the groceries. This indicated there is a potential for some cashiers to improve their work technique.
\end{abstract}

Keywords: upper extremity disorders, workstyle, task analysis

\section{Introduction}

Checkout cashier work can be repetitive and handintensive especially when the EAN-codes of a large number of groceries need to be turned towards the scanner. Work involving highly repetitive arm movements is related to elbow disorders [4].

The prevalence of discomfort/pain in the elbow, wrist or hand is 1,7-1,8 times higher among Swedish female cashiers compared to female workers with varied and mobile work $[1,3]$. Work technique e.g. the size and speed of wrist movements, is related to the prevalence of pain in the upper extremities [2].

The aim of this study was to analyze if there were differences between cashiers in to what extent they use large or small wrist movements when scanning groceries.

\section{Method}

Seventeen $(\mathrm{n}=17)$ cashiers from three different stores, one supermarket in a city center and two large supermarkets situated in shopping malls, were videoed during their ordinary work. All groceries from three customers per cashier were counted. Two researchers counted how many of the groceries that had to be turned towards the scanner and how many groceries that were handled with large wrist motions ( $>15$ degrees flexion/extension, ulnar/radial deviation). The researchers made this assessments together in consensus. The movies were played backward and forward in slowmotion and still images were used. In total, handling of 1009 groceries were analyzed. The ratio: (number of groceries that were handled with large wrist motions)/(number of groceries

\footnotetext{
* Corresponding author. E-mail: peter.palm@medsci.uu.se
} 
that had to be turned towards the scanner) were calculated.

\section{Results}

Sixty-four percent $(64 \%)$ of the groceries had to be turned in right direction towards the scanner. There were large variations among the cashiers in how much they used small or large wrist movements when handling the groceries. Three people used large wrist motions for less than a quarter of the groceries needing to be turned (figure 1). One person used large wrist movements also for groceries that did not need to be turned(cashier no 17 in figure 1).

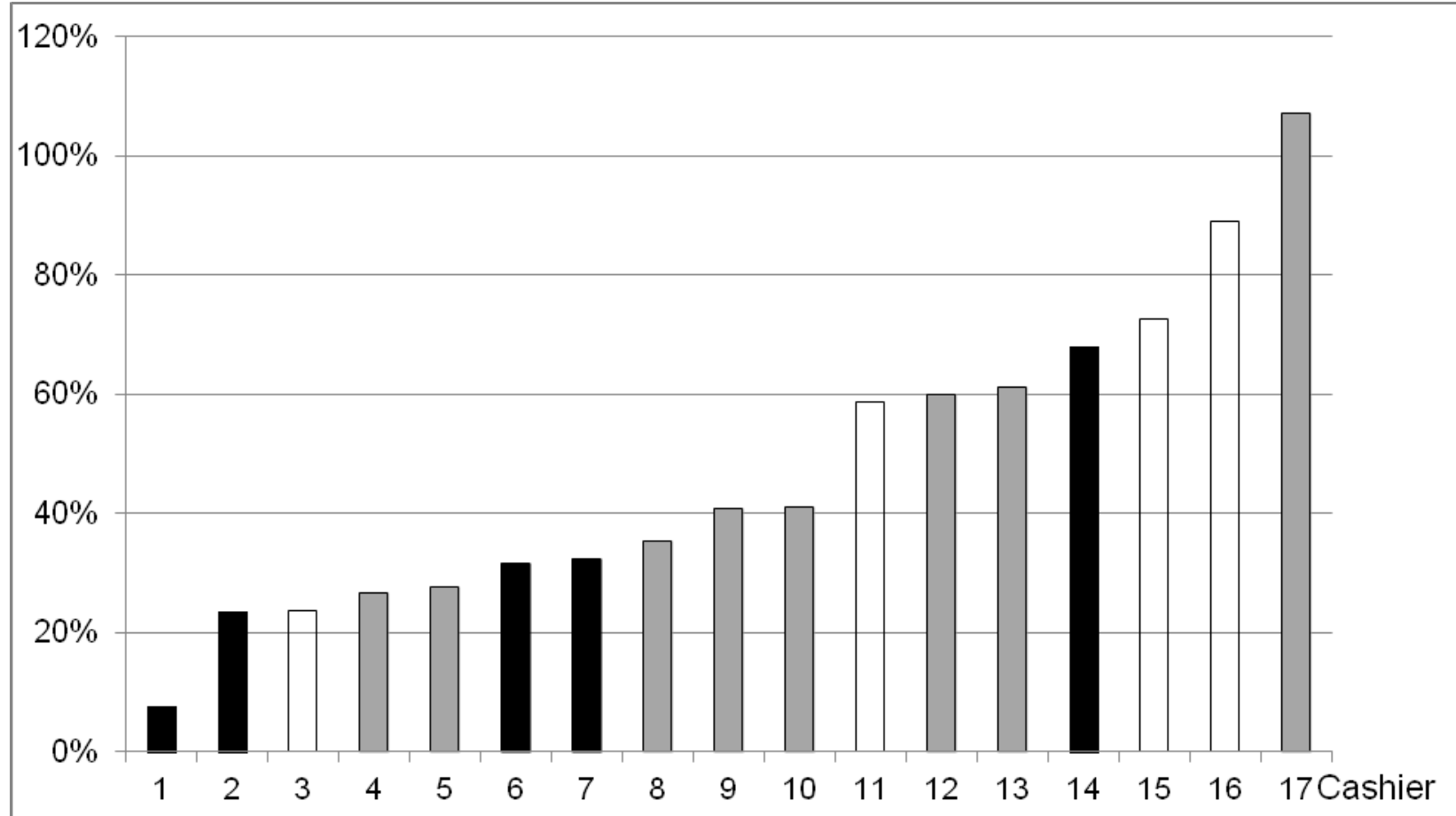

Fig 1. Proportion of groceries that were turned towards the scanner with large wrist movements in relation to number of groceries that had to be turned, for each cashier. Each color represents the three different stores.

\section{Discussion}

In this material there were large variations in work technique in to what extent the cashiers used large or small wrist movements when scanning groceries. This indicates a potential for improving work technique among cashiers who use unnecessary large wrist motions when turning the groceries. Alternative techniques to scanning EAN codes for registering groceries such as printing EAN codes on several sides of the groceries and informing customers to turn
EAN codes towards the scanner, might also reduce cashiers' exposure to repetitive wrist movements.

\section{References}

[1] I. Balogh, K. Ohlsson, G.-Å. Hansson and C. Nordander, Att arbeta i livsmedelsbutik [Working in grocery stores], Report No. 5, Lund University, Occupational and Environmental Medicine, (2011).

[2] M. Feuerstein and T. E. Fitzgerald, Biomechanical factors affecting upper extremity cumulative trauma disorders in sign language interpreters, Journal of Occupational Medicine, 3 (1992), 257-264. 
[3] C. Nordander, K. Ohlsson, I. Akesson, I. Arvidsson, I. Balogh, G.-Å. Hansson et.al, Risk of musculoskeletal disorders among females and males in repetitive/constrained work, Ergonomics, 10 (2009), 12261239.
[4] R. M. van Rijn, B. M. A. Huisstede, B. W. Koes and A. Burdorf, Associations between work-related factors and specific disorders at the elbow: a systematic literature review, Rheumatology, 48 (2009), 528-536. 